\title{
Making infrastructure work for the poor: Development benefits of PV systems in two Bangladesh communities
}

\author{
H U Chowdhury \\ Department of Economics, Kazakhstan Institute of Management, Economics and Strategic Research, \\ Almaty, Republic of Kzakhstan
}

\begin{abstract}
Bangladesh has been suffering from acute shortages of energy and the gap between demand and supply of energy has been gradually increasing. As the country has very limited natural resources, except natural gas, it largely depends on imported fuel. But due to financial and technical inability, it is almost impossible for Bangladesh to extend fossil fuel based power distribution networks to the rural community. Moreover, the low purchasing power is also a limiting factor for the rural population to have access to the formal energy market. As a result, rural society is in a most vulnerable situation from the side of energy consumption. Against this background, this study aims to examine the link between energy and economic development by collecting primary data from two Bangladesh communities which use solar energy. The study made an attempt to find out the economic and social impacts of sustainable rural energy on poor people and governance and management of these infrastructure projects. The study found that providing electricity through solar energy has a multidimensional affect on rural livelihood. It not only improves the living standard of the rural people but also improves access to information, better health for women and children and an extension of indoor income generating activities. However, poor maintenance, lack of technical knowledge, and training hampered the operation and repairing functions of solar energy technology in the rural community. For improving effective management of solar energy technologies, there is a need to increase end user awareness of system use, end-user capacity to troubleshoot problems, and level of service, quality and timeliness of repairs. The local government should come forward to increase awareness among beneficiaries and ensure the effective functioning of these systems.
\end{abstract}

Keywords: infrastructure, solar energy, development, governance, poverty, Bangladesh

\section{Introduction}

Infrastructure is an essential part of the development of any country. It is about providing basic services related to water, sanitation, modern energy, roads and other aspects of transport, and access to modern information communications technology that people need in everyday life. Infrastructure services cover a wide range of users and edifice the environment in which people live and work. The lack of basic infrastructure is a defining characteristic of poverty. Though the lack of infrastructure hurts both the rural and urban poor, no one is more disadvantaged than the rural poor. The absence of basic infrastructure services limits their access to markets and effectively excludes them and their children from education, health and other services.

The availability of reasonably priced and sustainable energy to all people is important for the achievement of the Millennium Development Goals (MDGs), and its contributions can help to meet the targets in various ways. Energy is a precondition for poverty alleviation, as targeted in MDG 1 , since it enables income-generating activities and the establishment of micro-enterprises. Similarly, energy helps to alleviate hunger and meet most of the other social and welfare-related MDGs by providing the light and power that the achievement of these goals critically depends on. Thus, infrastructure improvements have an indispensable contribution to make to attainment of Millennium Development Goals in Education and Health. As a result, the issue of 'energy for the poor' is consequently becoming one of the principal issues in the global debate on energy.

In Bangladesh, a major portion of the population located in off-grid areas will not be able to get electricity in the foreseeable future due to several constraints, including low consumer density and inaccessibility. The elimination of poverty remains the primary objective of the government's development efforts. Keeping the socio-economic reality in 
view, the government has given top priority to poverty alleviation by using resources efficiently through integrated project development in rural areas.

Rural electrification is a key element in rural development and can bring tangible social and economic benefits to poor, particularly rural populations. The possible benefits can include household lighting, the ability to refrigerate food and medicine, and food processing. Access to electricity also can make grain milling and agricultural processing less expensive and more convenient. The presence of electricity in a village also can result in better lighting for schools, health clinics and public streets. The use of electric pumps can improve productivity in agriculture and provide cleaner water for the public water supply. Finally, the availability of electricity can have a positive psychological impact through a lessening of the sense of exclusion, remoteness, and vulnerability often felt by rural populations.

\subsection{Literature review}

Barkat et al $(2002)^{1}$ carried out a very rigorous study on the Economic and Social Impact of a Rural Electrification program on Bangladesh, where they found that access to rural electrification has a significant impact on the reduction of both incomepoverty and all dimensions of human poverty (health, education and women empowerment). The study also found that rural access to this commodity has a deep-rooted impact on agricultural development, industrialization, and business and commercial activities. In addition, it has an impact on human capital formation through knowledge building mediated by electricity-driven media exposure.

Biswas Wahidul K, and others $(2001)^{2}$ worked on a model for empowering rural poor through renewable energy technologies in Bangladesh. They found that renewable energy technologies (RETs) create income-generating activities for male landless and marginal farmers and for women from such households, while reducing environmental problems, like deforestation and indoor air pollution from cooking with poor quality fuels. It has been found that the welfare benefits for rural and poor people of having access to electricity are quite high. ${ }^{3}$ The use of one electric light bulb is far superior to kerosene lamps and candles.

A study on the impact of an energy infrastructure project was carried out under a DFID funded project for the benefit of developing countries on the assumption that energy infrastructure interventions have significant impacts on people's livelihoods. ${ }^{4}$ The study concluded that although it seems to have a positive impact, significant economic development does not automatically follow from the introduction of energy infrastructure and the provision of energy services.
Garcia Albert U. (2002) $)^{5}$ carried out a study on an Assessment of a Solar Energy Program to determine the social, economic and technical impact of the solar home system program in Isla Verde, Batangas City in the Philippines. The study found that solar electrification has brought changes in the lives of the solar users and the study categorized these changes from the social, economic and technical point of view. Solar energy made it possible to modernize the household facilities such as house type, toilet, cooking and water facilities etc. because the complementary undertakings paved the way to transport the commodities around the island. Solar home system (SHS) bridges the gap between life in the city and the island through access to media (TV, radio, etc.), efficient lighting, communication through UHF radio etc. It facilitates the modification of social activities thereby giving extra or extended time for social activities like entertainment, chatting with neighbours, village meetings, social drinking for men, study time for children etc. It was also found that the establishment of the SHS paved the way for the peoples' organizational maturity by the formation of other associations after the founding of the solar owners organization.

There is an improvement in the community through the aspects of peace and order, participation of community members through community affairs, socio-economic status of community members and the level of development of the village. Extended time for people's economic activities happened for mat weaving, packing of tropical fish, livestock raising, rice cake making and the service hour of the sari-sari store (variety store or kiosk).

The SHS has brought savings to the users because it is cheaper to use than kerosene although the initial cost is high. It gives way to the establishment of the consumers and credit cooperative, thus, in one or another has been helping the users for their financial problems. The unavailability of technicians has made the SHS users to be more selfreliant because they have now the capability to address the technical problems of their electrical system. Vijay Laxmi and others ${ }^{6}$ found that in the case of bio-fuel use, time spent and hardship suffered in fuel collection, health impacts suffered from air pollution, increased burden of cleaning utensils, walls, floors and clothes, ecological changes and so on, are negative externalities.

Against this background, the purpose of the study is to focus on an impact assessment of sustainable rural energy projects, with a focus on poverty and gender implications. The present study could not cover the impact assessment for all options of SRE except solar energy. As a result, this paper will exclude projects on wind, biomass and micro-hydro. Within the solar option, though the SRE project has explored a number of PV technologies considering socio-economic conditions, 
availability of resources, technological options and dissemination possibilities, the present study considers the following two projects for assessing the impact on poverty and MDGs:

- Cluster village electrification by solar PV at Nalitabari, Sherpur; and

- Solar PV electrification at a community clinic at Terokhada, Khulna.

The rest of this paper is organized as follows. Section 2 presents the methodology of the study. Section 3 presents the description of the infrastructure project related to sustainable rural energy (SRE) and, Section 4 presents the findings of the study and Section 5 presents the key lessons learnt from the project. Finally, Section 6 is the concluding section.

\section{Objectives and methodology of the study}

The objective of the study is to assess the direct and indirect impacts of the SRE projects on human poverty reduction and on human security. More specifically, the objectives of the present study are: (i) to look at the economic and social impacts of sustainable rural energy on poor people at the local level; (ii) to look at the governance and management of these infrastructures; and (iii) to identify lessons learned and suggest policy options in each of the infrastructure projects with a view to replication micro-macro linkages.

The study collected information by Focus Group Discussions (FGD) to assess the poverty and gender implications of the SRE. The aim of this approach is not only to extract information, but also to generate discussions to facilitate community analysis and action planning. As the participatory approach generates detailed qualitative data specific to the particular communities being studied, the data generated often cannot be generalized to a broader area. However, the approach builds capacity through discussion with community for planning and managing the project. In this cycle, the different groups in a community assess the situation, identify areas for change, and take collective action.

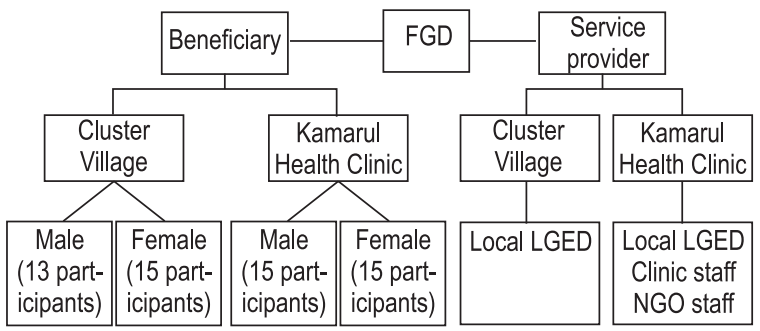

Within this framework, the study made attempts to find out the link between energy and economic development by collecting information from project beneficiaries, including both males and females. The benefits of having female respondents are very important in a male-dominated society of rural Bangladesh, and it is encouraging to see a good number of women coming forward to talk to us and express their views. Information was also collected from the local officials of LGED and NGOs to know the present status of the service and the governance issues, and to assess the social and economic impacts of the project. The study also utilized information as available in various secondary sources.

\section{The infrastructure project}

As Bangladesh has enjoyed steady growth in recent years, the infrastructure to supply electricity to the economy has not kept pace with this growth. The gap between demand and supply is gradually increasing. As a result, Bangladesh has been suffering from acute shortages of energy where rural society is in a most vulnerable situation. As the country has very limited natural resources, except natural gas, it largely depends on imported fuel. The use of imported fossil fuel is not only harmful for the environment and long term sustainability of the economy of Bangladesh but also, due to financial and technical inability, it is almost impossible for the country to extend fossil fuel based power distribution networks to the rural community. Moreover, the low purchasing power is also a limiting factor for the rural population to have access to the organized energy market.

In rural Bangladesh, the major demand for energy in the household activities is for cooking and lighting while that in commercial activities is irrigation and crop processing. Having realized the increased demand for rural energy, the Local Government Engineering Department (LGED) of Bangladesh has initiated a Sustainable Rural Energy (SRE) project within the overall framework of the UNDP financed Sustainable Environment Management Programme (SEMP) to explore opportunities for community based renewable energy (RE) options for different application and their use. Activities under SRE encompass (1) demonstration of $\mathrm{RE}$ installation, (2) establish a renewable energy information network (REIN), and (3) capacity building through training. In the contest of natural resource endowment and livelihood of the rural people, SRE has limited its activities within four renewable energy options and these are solar, wind, biomass and micro-hydro.

The following SRE projects within four renewable energy options have already been implemented under the Sustainable Environment Management Programme (SEMP).

\section{1 Renewable energy technology demonstration}

Solar energy

- Solar village demonstration programme at Baliadangi, Thakurgaon 
- Demonstration plant in solar market electrification at Shalikupa, Jhenaidah

- Cluster village electrification by solar PV at Nalitabari, Sherpur

- Solar PV electrification at a community clinic at Terokhada, Khulna

- Demonstration solar plant in a tourist spot at Goznee, Jhenaighati

- Tribal community electrification by solar PV at Rangamati

- Solar demonstration for IT development at Kutubdia, Cox's Bazar

- Solar PV demonstration for IT development at Kutubdia, Cox's Bazar

- Large scale comprehensive solar electrification at a coastal community

Bio energy

- Two Biogas plants at two sites in the country

- One bio-gasifier plant at one site of the country

Wind energy

- Water pumping unit (windmills) at two different sites

- Wind solar hybrid systems at Kuakata Sea Beach

- Twenty wind monitoring stations in different parts of the country

Micro hydro

- One small micro-hydro power unit

\subsection{Brief description of the selected} projects

3.2(A) Solar Electrification Cluster Village, Sherpur, Bangladesh

This is a demonstration solar photovoltaic project for a cluster village called 'Asrayan'. 'Asrayan' is a government's campaign for the eradication of poverty, providing shelter and improving the quality of livelihoods of landless poor. The cluster village is located in the government's land - called 'Khash land' - of different parts of Bangladesh, where landless poor are rehabilitated and sheltered.

A Solar Photovoltaic System (SPV) has brought enormous potential for socio-economic development of the rural people in off-grid areas. The objectives of this project are twofold: firstly, to assess the potential of this technology in improving the quality of landless poor, and secondly, to verify whether the landless groups can organize themselves to support operation and maintenance of the system. The installation completed in 1999 in Nalitabari Upozila in the Sherpur district is to provide solar electricity in 60 houses of the landless poor.

\section{2 (B) Solar Electrification at a Rural Health}

Clinic

Within the overall framework of the Sustainable Environmental Management Programme (SEMP) sponsored by the UNDP, an LGED selected Kamarul Community Health clinic under

The projects at a glance

\begin{tabular}{|c|c|c|}
\hline Item & Project A & Project $B$ \\
\hline Name of the Project & $\begin{array}{l}\text { Cluster Village electrification by solar PV at } \\
\text { Nalitabari }\end{array}$ & Solar PV electrification at a community clinic \\
\hline Location & Boradubi, Upazila: Nalitabari, Dist.: Sherpur & Boradubi, Upazila: Nalitabari, Dist.: Sherpur \\
\hline System Capacity & 1725 Watts & 1500 Watts \\
\hline Installation Year & 1999 & 2001 \\
\hline $\begin{array}{l}\text { Investment Cost of the } \\
\text { Project/ Allocation } 7\end{array}$ & US \$ 24200 & $\mathrm{~N} / \mathrm{A}$ \\
\hline No. of Beneficiary & 60 houses of landless poor & $\begin{array}{l}\text { About } 30000 \text { people getting health care } \\
\text { service }\end{array}$ \\
\hline $\mathrm{O} \& \mathrm{M}$ & By Beneficiary Committee & $\begin{array}{l}\text { The responsibility of } \mathrm{O} \& \mathrm{M} \text { has been } \\
\text { entrusted with a local NGO, Shastho o Jono } \\
\text { Unnayan Sagstha (SJS) }\end{array}$ \\
\hline $\begin{array}{l}\overline{\text { Beneficiaries }} \\
\text { participation in O \& M }\end{array}$ & 1 TK. per day ${ }^{8}$ & $\begin{array}{l}\text { Clinic authority deposits TK. } 1000 \text { per } \\
\text { month to the SJS }\end{array}$ \\
\hline Funding Agency & UNDP & UNDP \\
\hline Implementing Agency & LGED & LGED \\
\hline $\begin{array}{l}\text { Objective and Target } \\
\text { of the Project }\end{array}$ & $\begin{array}{l}\text { Firstly, to assess potential of this echnology in } \\
\text { improving the quality of landless poor. } \\
\text { Secondly, to verify whether the landless } \\
\text { groups can organize themselves to support } \\
\text { the operation. }\end{array}$ & $\begin{array}{l}\text { To deliver an adequate level of health care } \\
\text { services in remote regions by providing a } \\
\text { reliable source of electricity. }\end{array}$ \\
\hline
\end{tabular}


Terokhada Upazila in Khulna district is to deploy PV technology for facilitating better medical health care to rural people. It may be mentioned that the clinic is located at a remote place which is about $13 \mathrm{~km}$ away from Upazila $\mathrm{HQ}$ and there is a very little prospect to cover the area under a national grid network in the near future. The objective of this project is to deliver an adequate level of health care services in remote regions by providing a reliable source of electricity. Electrical power is often fundamental to the health services and, in its absence at any moment, can have dire consequences.

Under this initiative, a $1.5 \mathrm{kWp}$ PV system has been installed to provide electricity to OT lamps for medical surgery and a refrigerator for vaccines, blood preservation in addition to other medical equipments Moreover, clinic lightings, fans and a TV facility have also been incorporated considering patients' comfort. Operation and maintenance of this system is being done by the clinic authority.

\section{Findings}

\section{A. Solar electrification cluster village, Sherpur, Bangladesh ${ }^{9}$}

PV Technology for the landless poor started in 1999 to provide electricity for room lighting to 60 families and TV in community centres for information and entertainment. This cluster village, which is known as 'Asrayan' and is inhibited by homeless people as previously mentioned, is located at Baradubi in the district of Sherpur. Sixty families in six barracks are living in this Asrayan Kendra. Note that ten families are living in each barrack.

In each barrack, there are 12 lights including two lights that are specially arranged for security purposes and set in the front and backyard. In total, 72 lights were allocated to this cluster village.

As most of the families living in the 'Asrayan' are very poor, we try to determine the impact of solar electrification on their earning potentiality. Do you think that solar electrification enhances your income generating activities? In response to this question most of the female members replied in the following way: Before electrification, we didn't have any spare time in the whole day as we had to engage in household activities including preparation of meals for the whole family. In the absence of electricity, it was impossible for us to pursue any income generating activities because the sunset provision limits our duration of work. After solar electrification, we are getting plenty of time for 'sewing' particularly at night. Don't you think that this is a good opportunity for us to earn more by utilizing our extra time? (a female household member of Baradubi Asrayan in the Sherpur District). Solar electrification in the household level enables expansion of income generating activities particularly home based economic activities in the rural life.

From Figures 1 and 2, we see that electrification has a positive impact on scope for work at night, expansion of local trade and business, generation of employment opportunities for the unemployed, and establishment of cottage industries and new shops.

'Electricity makes it possible for our life to be easier', said Fatema Begum, a member of a household at Asrayan. Now we can watch television and learn more about the role of women in a society. We have seen how rural women are playing a significant role for fighting poverty by taking loans from different NGOs. Besides watching movies, we can understand the different developmental activities, like food for work, old age pension for destitute woman, etc., that have been introduced by our government for reducing poverty and improving the livelihood of the poor. We have also learned how boys and girls need to be treated equally, the role of education in their life and the necessity of taking extra food and health check ups during our pregnancy, said another woman named 'Umme Kulsum'. We have also learned the importance of family planning in a society like ours. 'Electricity has brought everything nearer to our door', said Jorna Begum. From the above observation, we can deduce that electricity has been playing the role of mediating agent for social and cultural development.

'The lighting from solar energy is much more compared to lighting from kerosene lamps but the price per unit of lighting for solar is substantially lower', said Rezaul Karim (a male household member of Baradubi Asrayan in the Sherpur District). Our children could not even read properly due to poor light from kerosene lamps, which is also damaging for their eyes. Besides, there is a significant fire risk from the use of kerosene lamps. The study has confirmed that there is an increase in the quality of life and satisfaction from the provision of electricity for households.

Education is a key input of human development, which is a condition of enlarging people's choices and opportunities. Human development is not possible without the providing of benefits of electricity to the population. As a result, the study made an attempt to know the role of electricity in changing the attention and willingness towards children's education and their attendance in school.

The study found that electricity increases the awareness amongst parents by strengthening the knowledge-base due to access to TV. The study also found that children now devote more time for education as they have sufficient light for study after sunset. Among all male FGD participants, $54 \%$ said attention and willingness to study have increased and $15 \%$ said that school attendance has increased with the availability of electricity. The corresponding figures for female FGD are $64 \%$ and $21 \%$ respectively. 


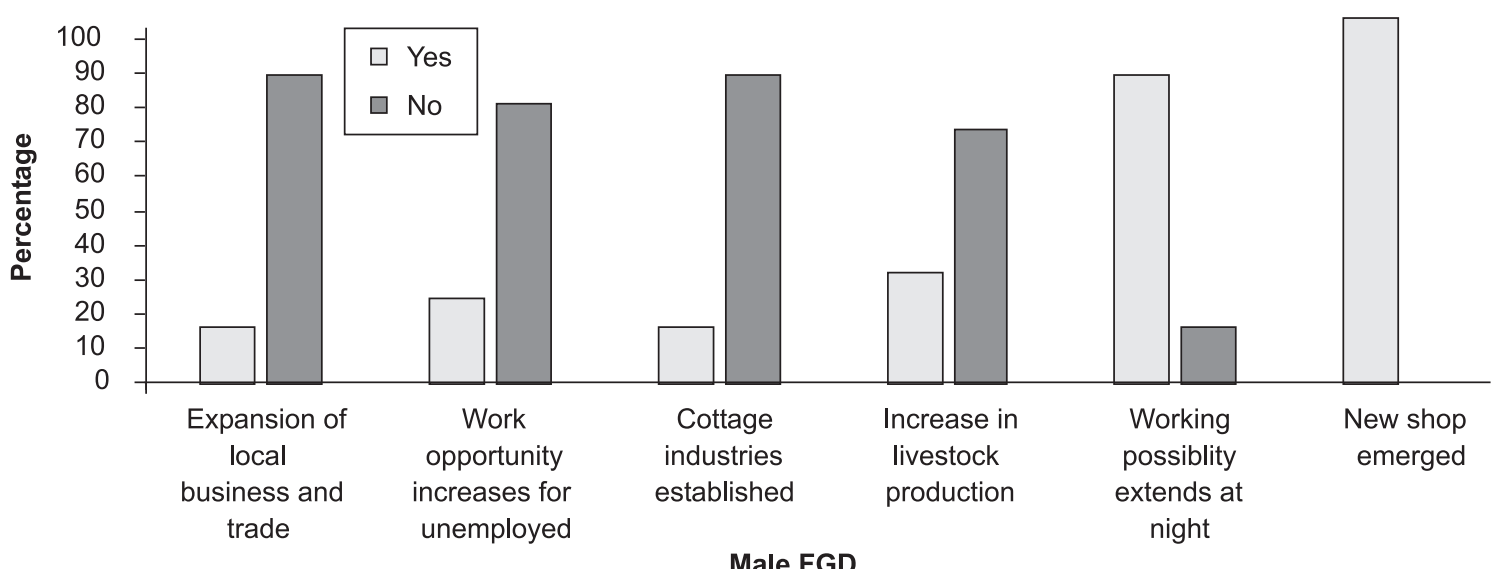

Figure 1: Perception of respondents in FGDs

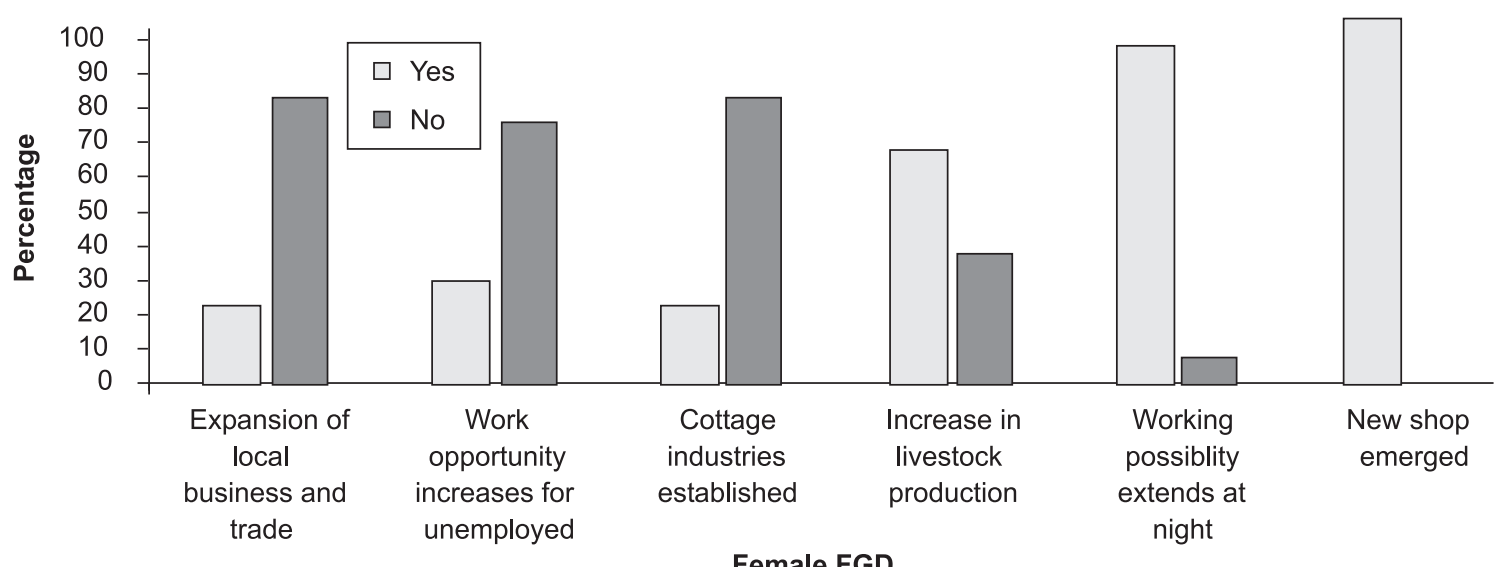

Figure 2: Perception of respondents in FGDs

All households believed that security had increased due to electrification by the solar energy system at Asrayan. The availability of light throughout the night reduces the incidence of theft and robbery, which was very frequent before electrification and now it has become difficult due to the availability of light at the front side and backyard of each barrack.

As the latrine is far from our home, it was diffi-

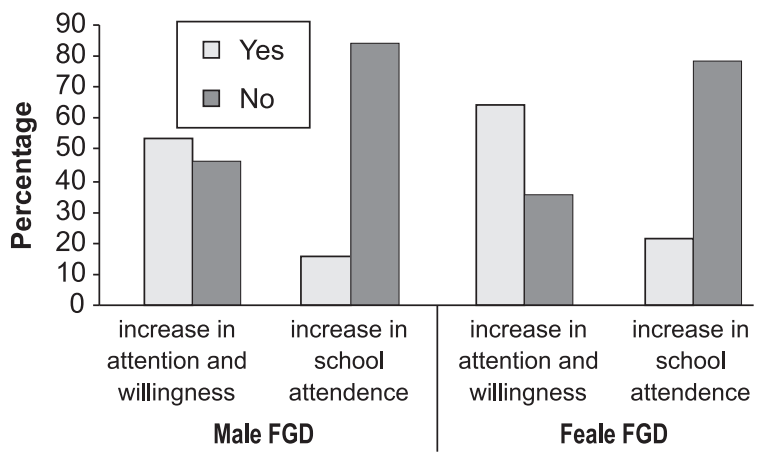

Figure 3: Children's attention and willingness to study after solar electrification cult for old age people and children to use it particularly at night before electrification. Due to electricity, old age people and children of the 'Asrayan' can use the latrine very easily particularly at night. Electricity connection increases the mobility at night. Most of the respondents believed that they can take care of their family and children when they become sick. Moreover, pregnant women feel better due to electricity.

The study found that most of the male FGD participants are day labourers, which is their major source of income for their livelihood. A few of the FGD participants have income earning opportunities from livestock, although having livestock in rural households is a common practice, especially in an agro-based country like Bangladesh. The reason might be that most of the households inhabited in the 'Asrayan' are landless so either they have very limited homestead land or no land at all. So they are unable to provide food and accommodation for domestic animals.

As the 'Asrayan' is located in a very remote area, most of the men used to return home from work before sunset as there was a risk of potential theft and robbery. After solar electrification, they are 
enjoying extended hours of work, which enables higher income through opportunities to engage in increased economic activities.

The study observed that electricity has the following positive impact on both male and female respondents of the Asrayan:

- awareness of crucial public health issues

- seeking treatment by medically competent people while sick

- use of medically trained people in child delivery

- use of TT immunization

- rate of full immunization of children (vaccines against 6 diseases)

- intake of Vit-A capsules to prevent night-blindness among children

- use of family planning methods

- use of hygienic latrines

The significant impact of electricity in people's health-hygiene-sanitation improvements is mediated through TV viewing, radio listening, easy availability and accessibility to the health centre.

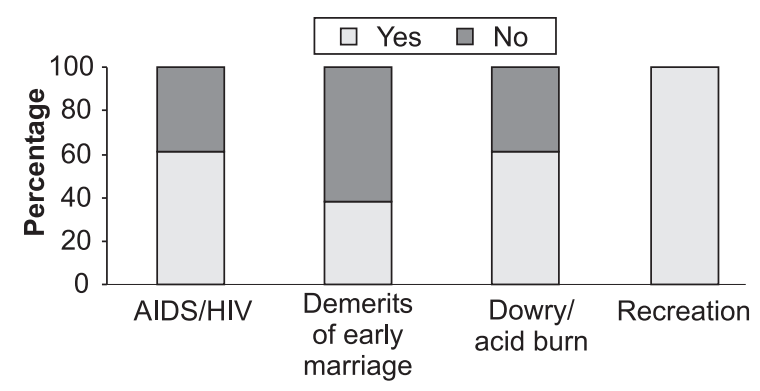

Figure 4: Increase in awareness due to watching TV

It is observed from the Figure 4 that awareness from respondents increase about AIDS and the merits of early marriage. Now the respondents, irrespective of men and women, are more aware and against the dowry and acid burn. ${ }^{10}$ The study has found that all of the respondents like to watch TV, which brings more recreation in their life.

Most of the respondents believed that after the installation, they obtained the benefit of the solar electrification for about 11 months only. They did not pay any extra cost for getting this electricity connection. During the consumption of this service, they deposited TK. 20 per month for each bulb to the local LGED office for the purpose of repairs and maintenance.

\subsection{Perception}

Women's perception towards their children's education, ideal-age at marriage, ideal family size, young women's job outside the village and dowry have increased due to solar electrification. In addition, security of mobility at night, husband's consultation on major decision issues, male-female debate in health care and educational spending etc. have positively impacted on the project beneficiaries.

What Will You Do if You Have More Energy? The following scenario illustrates rural people perceptions of the increased energy supplies. A large majority of $60 \%$ think that it would increase economic activities and create more jobs, $12 \%$ think that it would improve their lifestyle, and $20 \%$ hope for more business etc. This finding implies that life in rural areas, both in terms of income, education, and entertainment, would change if more energy was made available. In the social context, it would reduce migration to urban centres, as well as impact on population growth.

\subsection{Governance}

Local Upazilla Parisad selected the site to install PV technology at the cluster village. Microelectronics and Rahim Afroj supplied three and four solar units respectively. The present study has found that a solar electrification system at 'Asrayan' is in a very critical condition. Trees have already covered most of the 'solar panel'. The users are deprived of consuming this service due to lack of proper maintenance for about the last three years.

Most of the bulbs supplied at the initial level were damaged after one year of usage, and there was no replacement thereafter. Each household deposited Taka 20 per month for more than one year to the local LGED office, hoping that they will get a proper repairing and maintenance service from LGED. The fact is that the cost of each bulb is very expensive as this solar electrification runs under a DC system.

The system has collapsed due to lack of proper repairing and maintenance. The system has become ineffective because the battery and bulbs become damaged, said one official of the local LGED. Insufficient funds and lack of skills are the major obstacles for repairing and maintenance. It is an urgent necessity to involve local people for proper monitoring and maintenance of this infrastructure project. The governance system of rural electrification through sustainable rural energy must be improved for providing repair and maintenance services.

'The Government should come forward to train our people for effective running of this system and form a 'committee' to supervise the whole thing', said Rizia Begum, an inhabitant of the Asrayan. Since the poor have weak social networks and they are usually excluded from mechanisms that allow their voices to be heard, formation of a committee can play an important role in extending people's participation in the monitoring and maintenance function.

\section{B. Solar electrification at rural health clinic (KHC)}

Under the SRE project, solar electrification was pro- 
vided to the Kamarul Health Clinic in Terokhada Upazila in the Khulna district in 2001. Along with electricity connection, a refrigerator was provided to preserve vaccines, blood etc. The Kamarul Health clinic is located at a remote place, which is about 13 $\mathrm{km}$ away from Upazila $\mathrm{HQ}$, and there is very little prospect of covering the area under the national grid network in the near future. The overall objective of this project was to improve health care delivery among the rural communities in Kamarul and nearby areas of Terokhada Upazila.

Coverage of the solar electricity at the Kamarul health clinic at the time of installation:

- 20 lights /bulbs (each 7 watt)

- One ceiling fan

- One table fan

- OT light (included 7 lights ) each 35 watts

- One refrigerator

- One TV

Clinic staff and facility:

- Three general physicians and one surgeon

- Two nurses

- Ten beds and OT room

As the clinic has targeted marginalised and hard to reach communities, people who previously had little or no access to services are now getting improved health care from this clinic after solar electrification has been installed. The project has impacted positively on poverty reduction and the empowerment of women. The doctors and the nurse show a very enthusiastic attitude towards the patients.

The clinic came under solar electrification in 2001, though it was established in 1999. Before 2001 , the clinic maintained its energy supply from a diesel-driven generator. The fact is that before solar electrification, people usually hesitated coming to this clinic, as there was a risk of a power failure.

The distance of the Kamarul Health Clinic from other health centres is:

1. Terokhada Health Complex $-13 \mathrm{Km}$

2. Mollahat Health Complex $-10 \mathrm{Km}$

3. Kalia Health Complex $-25 \mathrm{Km}$
4. Shacheda Bazar Health and Family Planning Centre - $1 \mathrm{Km}$

5. Chunkhola Health and Family Planning Centre $-3 \mathrm{Km}$

6. Ghardanga Health and Family Planning Centre $-16 \mathrm{Km}$

Before electrification, women nearby the Kamarul areas only used to visit the clinic. After solar electrification, women are coming from even $40 \mathrm{~km}$ away from the Clinic. Old aged people are getting the most benefit from this clinic. Before the establishment of this clinic, people had to go to the Upazilla Health Complex, which is $12 \mathrm{~km}$ away from their village.

Due to the long distance to the Upazilla Health Complex and high transportation cost, most of the people of the Kamarul village do not visit the health complex unless they have faced a severe health crisis. Therefore, the establishment of the $\mathrm{KHC}$ has reduced these costs. Now they can frequently visit the clinic when the children catch a cold, suffer from a fever or get diarrhoea with a very low cost.

About $60 \%$ of women from Kamarul and its adjacent areas come to this clinic for child delivery. About $40 \%$ of women from the same area come to this clinic for getting health services just before and after child delivery. A major strategy to improve women's health was the provision of safe motherhood services. As a result, the clinic has made access to safe delivery facilities available to pregnant women, who would otherwise have given birth at home without skilled assistance.

Besides child delivery and other primary health care, the clinic provides services related to the following diseases:

- Typhoid

- Asthma

- Appendix problems

- Tumours

- Tubectomy

- Hernia operation - Herniotomy

- Brest tumour operation -Mastectomy

- Gall bladder stone - Cholelithiasis

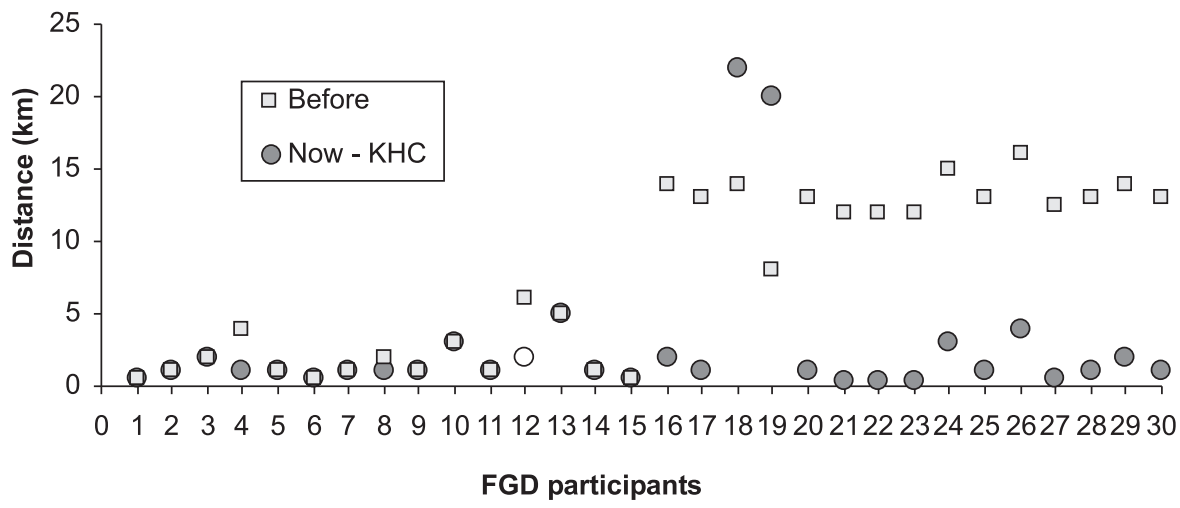

Figure 5: Distance from households to health centre 


\subsection{Community satisfaction}

Seventy percent of respondents to a question on whether they were satisfied with the diagnostic/treatment replied in the affirmative. Ninety percent were satisfied with the availability of the doctors at the clinic. The majority were satisfied with the availability of female health workers/nurses and labour room staff at the clinic. The price of the service is very reasonable and lower compared to other private clinics. ${ }^{11}$ As the KHC does not provide any medicine, availability of medicines is an area of concern. The majority of the respondents expressed satisfaction with the surgical operations, and child delivery. Most of the participants of our FGD, started to visit the clinic after the solar electrification was installed, which ensures effective operation and service through better equipment, test facilities and availability of staff.

The majority of the respondents considered their accessibility to better health services and the availability of medical staff as the most valuable elements, which has brought effectiveness due to solar electrification at the clinic. Improvements in health uplift the level of performance and productivity of individuals, thereby increasing their income-generating capacity.

With the installation of the solar electrification at the clinic, health care facilities in Kamarul and adjacent areas have increased. Increased immunization coverage has helped in reducing the incidence of childhood diseases. The rate of immunization of children (vaccines against 6 diseases) increased after solar electrification at the clinic. In the communities, information, education and communication concerning cleanliness, hygiene, and nutrition have increased people's awareness of health and disease, resulting in the reduced incidence of several diseases such as diarrhoea, tuberculosis and respiratory tract infections.

From both male and female FGD participants, the study found that among the rural people, there is an increase in awareness of crucial public health issues. After the establishment of this clinic, people are now seeking treatment from medically competent people while sick rather than from local practioners.

The strengthening of $\mathrm{KHC}$ by solar electrification has enabled people to obtain not only comprehensive primary health care but also to get services for some complex diseases that need operations. ${ }^{12}$ Improved accessibility and availability of services, coupled with increased utilization, have had a positive impact on the health status of the people, which might increase economic productivity and contribute to the reduction in poverty.

All FGD participants believed that the clinic is established in a proper place. It is very near to the bus stop and $1 \mathrm{~km}$ away from the Shacheda Bazar. People never face any problems for coming to the clinic even in the rainy season, as there is a road linked up with the clinic.

Some $30 \%$ of the FGD participants said that electricity generated from the system could not fulfil the $100 \%$ demand. However, they are satisfied with whatever the facility they are getting through utilization of the solar system.

\subsection{Management}

The Clinic authority deposits TK. 1000 per month to the 'SJS' ('Shastho o Jono Unnayan Sagstha', which is a local NGO responsible for the operation and maintenance of this infrastructure project) for repairing and maintenance purposes. From this deposited money, SJS meets up the repairing and maintenance costs. The system is providing consistently good power quality and the expected supply of electricity. "However, we are not utilizing the full capacity of the system as some bulbs have been damaged for long time. The refrigerator has not function well for the last 3 years', said the Director of the Clinic.

The solar panel of the electricity infrastructure at the health clinic was placed in a proper position so that it could get the sunlight properly. The battery and charge controller were kept inside the clinic. As a result, there is no security problem. Due to a nat-

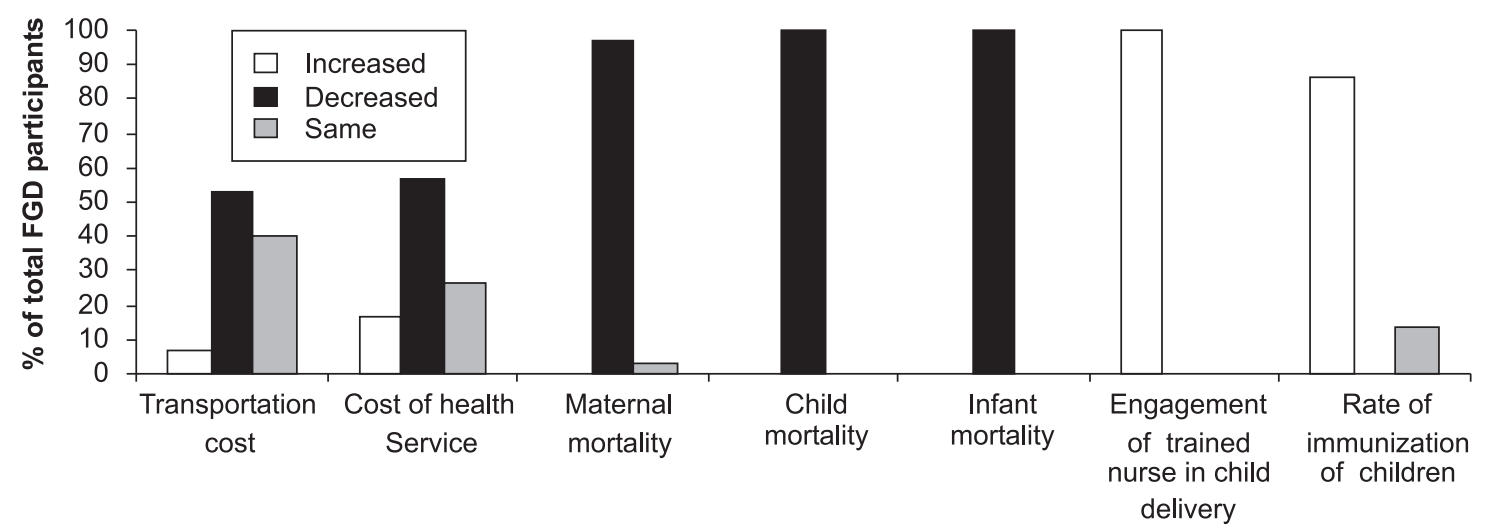

Figure 6: Impact of solar electrification at the Kamarul Community Clinic 
ural disaster and some other external causes, there was no record of damage to this infrastructure.

Local people were not involved in site selection, construction and repairing and maintenance of this electricity infrastructure. Most of the FGD participants said that involvement of local people is very effective particularly for maintenance of the project. At present three doctors of this clinic look after the operation and maintenance function. For this task, they follow the guideline provided by the LGED.

Though they have received initial training on how to look after this infrastructure, their knowledge is not sufficient enough to handle any difficult technical problem. For proper repairing and maintenance, LGED should provide intensive training to the local people. If LGED could provide intensive training for skills upgrade, the system would function more effectively. Presently, there is no scope to involve local people for the operation and maintenance of this infrastructure project, said one official of SJS, which is a local NGO involved with this project.

From its own source of earning, the clinic deposits of Tk. 1000 per month to SJS to meet up the cost of repairing and maintenance. From this deposited amount, SJS meets the necessary expense for repairing and maintenance. If the system could transfer from $\mathrm{DC}$ to $\mathrm{AC}$, the repairing and maintenance will be easier and less costly as most of the equipments is available in the local market. As the system is running under a DC system, it is not possible for the clinic authority or local NGO to purchase bulbs or any other equipment from the local market. The cost of each bulb under a DC system is more expensive ${ }^{13}$ compared to the AC system, and these are only available at the capital city, Dhaka. Due to the unavailability of equipment at the local market, the clinic authority/NGO could not replace the necessary bulbs that are already damaged.

\section{Key lessons learnt from the project}

- Community based renewable energy options are good practice in promoting a Renewable Energy based decentralized power generation system in remote off-grid areas.

- Major hardware of the solar systems are not locally ${ }^{14}$ available and affordable for immediate replacement. Locally available proper maintenance service, trouble shooting and updated information could bring more confidence to the beneficiary for using this technology.

- Though a good practice of generating funds from collecting contributed money regularly to meet the expenditure of operation and maintenance has been introduced, it is not sufficient to meet the expenses of the repairing and maintenance service. The objective of this fund generation is to hand over the demonstration plants to the beneficiary systematically in order to built a sense of ownership among them and, consequently, the beneficiary will take extra care to maintain their system and increased the life of those plants.

- NGO based operation and maintenance is much effective compared to local government administration.

- RET's do have an important role to play towards Energy Security especially for people living in remote and off-grid areas.

\section{Summary}

The greatest benefit of rural electrification for rural communities is better lighting quality and the education benefit associated with extended lighting at night. Other benefits include an improved access to information, better health for women and children, and an extension of indoor income generating activities.

- Income generation activities of the Asrayan people have been increased. Solar PV systems provided sufficient lights, which helped people to extend their income generation activities at night.

- Electricity has a positive impact on watching TV and listening to the radio.

- Access to electronic media provides the entertainment and education benefits by giving access to television, facilitate adult education and also giving people awareness of health care and family planning through the EPI programme.

- Solar lights encourage different income generation activities like small handicrafts and cottage etc in evening sessions.

- Female household members are better able to conduct all of their household responsibilities.

- Overall quality of livelihoods in cluster villages improved during their consumption of solar electricity.

- Providing electricity at community clinic improves the access to and quality of health care, access to medicines, presence of doctor(s)/health worker(s), and safety in and outside the home.

- Creating a public benefits fund would be useful to support wider access, or the development and diffusion of sustainable energy technologies.

- Poor maintenance, lack of technical knowledge, and training hampered the operation and repairing functions of solar energy technology at cluster villages.

- There have been problems with system reliability, and the need for guaranteed performance standards have been urged by beneficiaries of cluster villages.

- The system must function in an effective way. 
This means that there must be an appropriate level of service operation that is both reliable and predictable.

- Bottom-up planning and implementation of the project is important in order to ensure direct contact with the users as well as with local agencies, departments etc.

- Lack of information on equipment availability, costs, and barriers to financing the repairing and maintenance function are the main concern to the users of solar electricity at Asrayan.

- Better diagnosis and treatment capability and more qualified medical personnel have resulted in an improved health facility in the Kamarul areas.

- The Kamarul health clinic has made access to safe delivery facilities available to pregnant women, who would otherwise have given birth at home without skilled assistance.

- The strengthening of the Kamarul Health Clinic by solar electrification has enabled the people to obtain not only comprehensive primary health care but also to get service for some complex diseases that need operations.

For improving effective management of solar energy technologies, there is a need to increase:

- end user awareness of system use

- end-user capacity to troubleshoot problems,

- level of service, quality and timeliness of repairs.

Clearly, energy is seen to serve three main purposes: education, entertainment and lifestyle. Therefore, there exists a tremendous social benefit from supplying extra energy to these people. Even small amounts of electricity can greatly improve living standards and facilitate income-generating activities, not least in rural areas.

\section{Acknowledgement}

The author is grateful to Dr. Atiur Rahman for his invaluable supervision while writing this report.

\section{Notes}

1. Barkat et. al (2002). Economic and Social Impact Evaluation Study of the Rural Electrification Program in Bangladesh. Human Development Research Centre.

2. Biswas Wahidul K., Paul Bryce and Mark Diesendorf. (2001). Model for empowering rural poor through renewable energy technologies in Bangladesh. Environmental Science \& Policy 4:333-344.

3. Joint UNDP/World Bank Energy Sector Management Assistance Programme (ESMAP) 2000. Subsidies and Sustainable Rural Energy Services: Can we Create Incentives without Distorting Markets?
4. DFID. The impact of energy infrastructure project: A sustainable livelihoods analysis.

5. Garcia, Albert U. (2002). An Assessment of a Solar Energy Program: The Case of Isla Verde, Batangas City, Philippines, Master's Dissertation, University of Flensburg, Germany.

6. Vijay Laxmi, Jyoti Parikh, Shyam Karmakar and Pramod Dabrase - Household energy, women's hardship and health impacts in rural Rajasthan, India: the need for sustainable energy solutions.

7. Please see site 2 of Table 2 and 3

8. Taka (TK.) is the unit of Bangladeshi currency. At present 60 Taka (TK) $=1$ US Dollar

9. Though the installed capacity of the project is to provide electricity connection to 72 lights/bulbs and $1 \mathrm{TV}$ point for Asrayan people, the present study found that the condition of solar electrification at the cluster village is in a very critical condition. As a result, we asked the FGD respondents to give their assessment when the project performed very well for carrying out this impact study.

10. In Bangladesh, usually good-looking girls are the victims. Males are relatively less affected. Common causes are love affairs, enmity over land properties, and personal reasons. Children are also affected - they are the victims of circumstances.

11. The FGD participants indicated that the private clinics at Khulna charge TK. 30000.00 for a 'Prostatectomy Operation', whereas the KHC charges only TK. 7000.00 for the same operation.

12. The office of the $\mathrm{KHC}$ confirmed that during the last year, they did 148 operations. On average, 20 to 25 patients come to outpatients for services.

13. Price of 7 watt bulb $=$ TK. 550.00 and 9 watt bulb $=$ TK. 575.00

14. Here the word 'locally' means the nearby area/town of the infrastructure project installed.

\section{References}

Ali, Ershad M. (2002). Transfer of Sustainable Energy Technology to Developing Countries as a Means of Reducing Greenhouse Gas Emission-The Case of Bangladesh: Review of Relevant Literature. Discussion Paper No. 02.08. Department of Applied and International Economics, Massey University.

Ali, Ershad M. (2002). Energy Consumption Pattern in Rural Bangladesh-The Opportunity for New Zealand: A Household Survey. Discussion Paper No. 02.10. Department of Applied and International Economics. Massey University.

Barkat, Abul et. al. (2002). Economic and Social Impact Evaluation Study of the Rural Electrification Program in Bangladesh. Report submitted to NRECA International Ltd.-Partners with the Rural Electrification Board of Bangladesh and USAID for the Rural Power for Poverty Reduction (RPPR) Program.

Centre for Energy and Environmental Policy of University of Delaware (2001. Off-Grid Renewable Energy Options for Rural Electrification in Western China. 
Everatt, David, Nobi Dube and Moagi Ntsime (2004). Integrated Sustainable Rural Development Programme Phase I evaluation: Nodal Review.

Greenpeace (2001). Power to tackle poverty: getting renewable energy to the world's poor.

Hoyne, Seamus (2000). Renewable Energy Development through Community Ownership and Partnership (REDCOP).

Jefferso, Michael. Energy policies for sustainable development, United Kingdom.

Joint UNDP / WORLD BANK Energy Sector Management Assistance Programme (ESMAP) (2000). Subsidies and Sustainable Rural Energy Services: Can we Create Incentives without Distorting Markets?

Joint UNDP/World Bank Energy Sector Management Assistance Programme (ESMAP) (2003). Monitoring and Evaluation in Rural Electrification Projects: A Demand-Oriented Approach.

Laxmi, Vijay, Jyoti Parikh, Shyam Karmakar and Pramod Dabrase. Household energy, women's hardship and health impacts in rural Rajasthan, India: need for sustainable energy solutions. Indira Gandhi Institute of Development Research.

Mbewe, Abel (2000). Renewables and Energy for rural Development Theme Group. African Energy Policy Research Net work (AFREPREN).

Musa, Alabe (1996). Household energy consumption patterns in northern Nigeria. Energy for Sustainable Development, Volume II, No. 5.

United Nations Environment Programme (2000). Evolving Choices for Renewable Energy Technology and Po 1 i c $y$.

Wahidul K. Biswas, Paul Bryce and Mark Diesendorf (2001). Model for empowering rural poor through renewable energy technologies in Bangladesh. Environmental Science \& Policy 4: 333 - 344.

Wilkinson, Rona (2002) The impact of energy infrastructure projects on Poverty, Boiling Point 48/final, Schumacher Centre for Technology and Development, Bourton on Dunsmore, RugbyCV23 9QZ, UK.

Received 29 March 2005; revised 9 March 2006 